\title{
Perceived Morality among Undergraduate Students Belonging to Forward and Backward Caste: A Study of Mithila Region of North Bihar
}

Dr. Pramod Kumar Ram, PhD*

University Department of Psychology, L. N. Mithila University, Darbhanga - 846004, India

DOI:10.36348/sjhss.2020.v05i10.007

| Received: 27.09.2020| Accepted: 04.10.2020| Published: 10.10.2020

*Corresponding author: Pramod Kumar Ram

Abstract

A dynamic reviewer of conservative morality has generally been viewed that moral judgments express individual desires or accepted habits. It is indeed that complete human beings participate fully in the life of society and express all of their nature. Some impulses must be checked in the interests of society and others in the interest of individual development, but it is a person's relatively unrestricted natural growth and self-realization that makes for the good life and harmonious society. Thus, the present research endeavor was aimed at studying morality among undergraduate students belonging to forward and backward classes with special reference to Mithila region of North Bihar. In this study one hundred sixty $(\mathrm{N}=160)$ undergraduates were selected randomly from different constituent colleges of L. N. Mithila University, India. Data were collected through questionnaire schedule. Having collected the data, individual scores were obtained as per norms of the test for giving statistical treatment. Obtained results revealed the clear cut picture regarding the significance of difference in terms of their perceived morality between the group of forward and backward undergraduates studying in different colleges of L. N. Mithila University as their $t$ - value had been found significant statistically at .01 level of confidence. Moreover, no significant difference between the group of male and female undergraduates has been found within the group of forward and backward classes especially in Mithila region, although forward group of male and female undergraduates had shown higher degree of perceived morality as compared to backward class group. The present trends of results have been discussed in detail by highlighting the probable reasons prevailing in Mithila region.

Keywords: Morality, Undergraduate, Students, Forward, Backward, Caste, Mithila Region.

Copyright (C) 2020 The Author(s): This is an open-access article distributed under the terms of the Creative Commons Attribution license which permits unrestricted use, distribution, and reproduction in any medium for non-commercial use (Non - Commercial, or CC-BY-NC) provided the original author and source are credited.

\section{INTRODUCTION}

Morality is one of the important aspects of psychology which begins from the socialization process. The term 'morality' has been derived from the Latin word 'Mores'. The literal meaning of the word mores may be conceived as manners or customs. In this way morality is to be considered a behavior conforming to the moral ethical code or the social standards. It is important to mention here that behavior pertaining to morality is voluntary in nature because it comes with the transition from external to internal authority consists of conduct regulated from within. It is accompanied by the personal responsibility for the act. Under the preview of morality individual / personal gains or desires are generally of secondary importance, although, the primary importance for the morality is the consideration for the welfare of society under broad umbrella of ethics.
Morality indicates what is the "right" and "wrong" way to behave, for instance, that one should be fair and not unfair to others [1]. This is considered of interest to explain the social behavior of individuals living together in groups [2]. Results from past studies [3] or insights into universal justice principles [4] do not necessarily help us to address moral behavior in modern societies. This also requires the reconciliation of people who endorse different political orientations [5] or adhere to different religions [6]. The observation reveals the fact that "good people can do bad things" hence, we must look beyond the causes of individual deviance or delinquency to understand moral behavior. Similarly, these relate to (a) the social anchoring of right and wrong, (b) conceptions of the moral self, and (c) the interplay between thoughts and experiences. Thus, we can argue that these three key principles explain the interest of so many researchers in the topic of morality and examine the degree of significant difference between Forward and Backward caste especially in Mithila region of Bihar State. 
The question of the definition of morality is the question of identifying the target of moral theorizing. Identifying this target enables us to see different moral theories as attempting to capture the very same thing. And it enables psychologists, anthropologists, evolutionary biologists, and other more empirically-oriented theorists to design their experiments or formulate their hypotheses without prejudicing matters too much in terms of the specific content a code, judgment, or norm must have in order to count as distinctively moral.

There does not seem to be much reason to think that a single definition of morality will be applicable to all moral discussions. One reason for this is that "morality" seems to be used in two distinct broad senses: a descriptive sense and a normative sense. More particularly, the term "morality" can be used either:

- Descriptively to refer to certain codes of conduct put forward by a society or a group (such as a religion), or accepted by an individual for his / her own behavior, or

- Normatively to refer to a code of conduct that, given specified conditions, would be put forward by all rational people.

Which of these two senses of "morality" a moral philosopher is using plays a crucial, although sometimes unacknowledged, role in the development of an ethical theory. If one uses "morality" in its descriptive sense, and therefore uses it to refer to codes of conduct actually put forward by distinct groups or societies, one will almost certainly deny that there is a universal morality that applies to all human beings. The descriptive use of "morality" is the one used by anthropologists when they report on the morality of the societies that they study. Recently, some comparative and evolutionary psychologists [7, 8, 3] have taken morality, or a close anticipation of it, to be present among groups of non-human animals: primarily, but not exclusively, other primates.

Accepting that there are two uses or senses of "morality" - a descriptive sense and a normative sense does not commit one to holding that the "distinction between descriptions and norms - between what is and what ought to be - is obvious and unbridgeable", as some have held that it does [9]. To see this, note that it is obvious that there is a descriptive sense of morality. That is, it is obvious that one can sensibly describe the moralities of various groups without making any normative claims. And it should be equally obvious that that one might hold that a certain code of conduct would be put forward by all rational people under certain conditions without having any particular views about the nature of the is/ought gap or the possibility of crossing it.

Any definition of "morality" in the descriptive sense will need to specify which of the codes put forward by a society or group count as moral. Even in small homogeneous societies that have no written language, distinctions are sometimes made between morality, etiquette, law, and religion. And in larger and more complex societies these distinctions are often sharply marked. So "morality" cannot be taken to refer to every code of conduct put forward by a society.

In the normative sense, "morality" refers to a code of conduct that would be accepted by anyone who meets certain intellectual and volitional conditions, almost always including the condition of being rational. That a person meets these conditions is typically expressed by saying that the person counts as a moral agent. However, merely showing that a certain code would be accepted by any moral agent is not enough to show that the code is the moral code. It might well be that all moral agents would also accept a code of prudence or rationality, but this would not by itself show that prudence was part of morality. So something else must be added; for example, that the code can be understood to involve a certain kind of impartiality, or that it can be understood as having the function of making it possible for people to live together in groups.

As we've just seen not all codes that are put forward by societies or groups are moral codes in the descriptive sense of morality, and not all codes that would be accepted by all moral agents are moral codes in the normative sense of morality. So, any definition of morality - in either sense - will require further criteria. Still, each of these two very brief descriptions of codes might be regarded as offering some features of morality that would be included in any adequate definition. In that way they might be taken to be offering some definitional features of morality, in each of its two senses. When one has specified enough definitional features to allow one to classify all the relevant moral theories as theories of a common subject, one might then be taken to have given a definition of morality. This is the sense of "definition" at work in this entry. Moreover, an assumption suggested by the every one is that there is some unifying set of features in virtue of which all moral systems count as moral systems, although, Sinnott-Armstrong directly argues against an analogous hypothesis in connection with moral judgments, and also seems to take this view to suggest that morality itself is not a unified domain $[10,11]$. He points out that moral judgments cannot be unified by any appeal to the notion of harm to others, since there are such things as moral ideals, and there are harmless behaviors that a significant number of people regard as morally wrong: Sinnott-Armstrong gives example such as cannibalism and flag-burning. Whether people who condemn such behaviors morally are correct in those judgments is largely irrelevant to the question of whether they count as moral in the first place. SinnottArmstrong seems right in holding that moral judgments cannot be delimited from other judgments simply by appeal to their content. It seems quite possible for 
someone to have been raised in such a way as to hold that it is morally wrong for adult men to wear shorts. And it also seems plausible that, as he also argues, moral judgments cannot be identified by reference to any sort of neurological feature common and peculiar to them and them alone. A third strategy might be to claim that moral judgments are those one makes as a result of having been inducted into a social practice that has a certain function. However, this function cannot simply be to help facilitate the sorts of social interactions that enable societies to flourish and persist, since too many obviously non-moral judgments do this.

\section{AIMS AND OBJECTIVES OF THE PRESENT STUDY}

Having looked upon the available literature, it has been observed that non of the studies are available on the phenomena with particular reference to undergraduate male and female students belonging to forward and backward class of Mithila region. Hence, the present piece of research endeavor is planned to see the significance of difference between forward and backward in terms of their degree of morality. It is indeed that morality develops from the lap of parents and deals the whole process of socialization. It is also important to point out that Mithila region is having a very rich socio - cultural milieu in North Bihar which covers well known districts viz., Begusarai, Darbhanga, Madhubani, and Samastipur, These districts are still unexplored area so far as the study of morality is concerned. Thus, the present study is of immense value and it will fill the void of knowledge in area chosen by the present investigator.

\section{HYPOTHESES}

On the basis of broad aims and objectives of the present study the following hypotheses were formulated:

1. There will be no significant difference between forward and backward class undergraduates in terms of their degree of morality especially in Mithila region

2. There will be no significant difference between male and female undergraduates among the group of forward class in terms of their degree of morality.

3. There will be no significant difference between male and female undergraduates among the group of backward class in terms of their degree of morality.

4. Forward class especially in Mithila region of North Bihar will have higher degree of perceived morality in comparison to backward class undergraduates.

\section{RESEARCH METHODOLOGY Sample}

For the present piece of research work one hundred sixty $(\mathrm{N}=160)$ undergraduates were selected randomly from different constituent colleges of L. N. Mithila University, Darbhanga located at in and around Darbhanga districts, viz., Darbhanga, Madhubani, Begusarai, and Samastipur. Total subjects' age were ranged between 18 to 23 years. Break - up of the total sample are given below:

Table-1: Showing the break - up of the total sample as given below
\begin{tabular}{|l|l|l|l|}
\hline GROUPS & Male & Female & Total \\
\hline Forward Class (Upper Caste) & 40 & 40 & 80 \\
\hline Backward Class (SC/ ST, and OBC) & 40 & 40 & 80 \\
\hline Total & 80 & 80 & 160 \\
\hline
\end{tabular}

\section{Tools and Materials Used}

The following tools were used for the present piece of research work:

1. For measuring the degree of Morality - a morality questionnaire test developed by Pandey [12] was used. This test has 60 items covering six dimensions viz., justice, dutifulness, truthfulness, altruism, honesty, and love. Out of sixty items, 46 items are negatively phrased and remaining 14 are positively phrased. Each item was rated on Likert 5- point scale with the response categories (1) strongly agree, (2) agree, (3) undecided, (4) disagree and (5) strongly disagree. . In this test high score indicates higher degree of morality and low score indicates low degree of morality. The reliability of the test is .82 which confirms the efficacy of the test.
2. Biographical Information blank (BIB):

For taping information regarding the respondents' biographies, a 'Biographical Information Blank' (BIB) was also prepared that included sex, age , caste, marital status, Family Income, Mother's qualification, Father's Qualification, Types of family and number of dependents of father, etc and the respondents were requested to furnish these information.

\section{Procedure}

The above two test materials viz., Morality Questionnaire Test and, Biographical information blank were in printed form and were administered to all the undergraduates individually. All the undergraduates (male and female) were assured by taking them in to confidence that provided information will be kept strictly confidential and will be used for research purposes only. Having collected the responses to the 
items of the questionnaires, they were scored according to the procedure and the individual scores were obtained for giving statistical treatment and finally presented in the tables.

\section{RESULTS AND DISCUSSION}

To achieve the objective of the present research endeavor obtained results are presented in tables. Table-2 reveals the clear cut picture pertaining to significant difference between the group of forward class and backward class caste of undergraduate students in terms of their degree of morality. It could also be observed from the Table- 2 that forward class caste of undergraduates (Upper class caste viz., Jha,
Mishra, , Roy, and Singh, etc) have scored higher degree of perceived reactions on morality test in comparison to backward class caste especially in Mithila region of North Bihar from where the present piece of research work has been completed. It is important to mention here that higher maximum scores of the test are 300 and they scored near about 200 i.e. above the average score. Hence, high significant difference has been found at 0.01 level of confidence. The formulated hypothesis i.e. there will be no significant difference between the group of forward class caste backward class caste undergraduates in terms of their degree of morality in Mithila region of North Bihar stands rejected.

Table-2: Showing Significant Difference between Forward Class Caste and Backward Class Caste Undergraduates in terms of their degree of Morality in Mithila Region of North Bihar

\begin{tabular}{|l|l|l|l|l|l|}
\hline GROUPS & N & Mean & S.D & t & Significance Level \\
\hline Forward Class Caste & $\mathbf{8 0}$ & $\mathbf{1 9 5 . 5 3}$ & $\mathbf{3 2 . 3 2}$ & & \multirow{2}{*}{ Significant at 0.01 } \\
\hline Backward Class Caste & $\mathbf{8 0}$ & $\mathbf{1 8 2 . 2 3}$ & $\mathbf{2 9 . 3 5}$ & $\mathbf{2 . 7 1}$ & \\
\hline
\end{tabular}

Table- 2 of the obtained results seems to be logical that the socialization process of forward class caste is different from the group of backward class caste. Forward class not only in Mithila region of North Bihar but throughout the nations are assumed far better than backward class (SC / ST / OBC), although, Govt. of
India have launched several programs for the upliftment such as socially, economically, morally and politically, etc of backward class but instead of these they are not taking care of pertaining to their lifestyle in accordance with the Indian modern norms. Hence, significant difference has been found.

Table-3: Showing Comparative Levels of Perceived Degree on Morality Questionnaire Test among the Undergraduate Students Belonging to Forward and Backward Caste in Mithila Region of North Bihar

\begin{tabular}{|l|l|l|l|l|}
\hline \multirow{2}{*}{ Levels } & \multicolumn{2}{|c|}{ GROUP } \\
\cline { 2 - 5 } & \multicolumn{2}{|c|}{ Forward Class Caste } & \multicolumn{2}{c|}{ Backward Class Caste (SC/ST \& OBC) } \\
\cline { 2 - 5 } & $\mathbf{n = 8 0}$ & Percentage & $\mathbf{n = 8 0}$ & Percentage \\
\hline High & $\mathbf{5 5}$ & $\mathbf{6 8 . 7 5} \%$ & $\mathbf{2 7}$ & $\mathbf{3 3 . 7 5} \%$ \\
\hline Moderate & $\mathbf{1 5}$ & $\mathbf{1 8 . 7 5} \%$ & $\mathbf{3 7}$ & $\mathbf{4 6 . 2 5} \%$ \\
\hline Low & $\mathbf{1 0}$ & $\mathbf{1 2 . 5} \%$ & $\mathbf{1 6}$ & $\mathbf{2 0} \%$ \\
\hline
\end{tabular}

\section{Mean value $=\mathbf{1 9 5 . 5 3}$}

Mean value $=\mathbf{1 8 2} .23$

In continuation of the Table $2 \& 3$ highlights the picture regarding comparative levels of perceived degree on morality questionnaire test among the undergraduate students belonging to forward and backward castes of Mithila region. It is evident from the table - 3 that 68.75 percent forward class undergraduates have shown higher degree of perceived morality in comparison to backward class group who reported only 33.75 percent. While 18.75 percent forward group of undergraduates have shown moderate level of perceived reactions on morality, 46.25 percent of backward class group have shown moderate level of perceived morality which is comparatively higher when compared to forward group. Moreover, 12.5 percent of forward class of undergraduate students group has been found to have low level of perceived morality in comparison to backward class group i.e. 20 percent which is high comparatively. Table-1 also indicated that forward class group in comparison to backward class group have higher degree of perceived morality as the Mean value of forward class of undergraduate students group $(\mathrm{x}=195.53)$ is found to be higher than that of the backward class group i.e. $\mathrm{x}=182.23$. Hence, the proposed hypothesis i.e. forward class of undergraduate students group will have higher degree of perceived reactions on morality scale than the backward undergraduate students, stands accepted. The above mentioned results can also be observed by illustrating following diagram with data table as given below: 


\section{Chart Showing Comparative Levels of Perceived Degree On Morality Questionnaire Test among the Undergraduate Students Belonging to Forward and Backward Caste in Mithila Region of North Bihar}

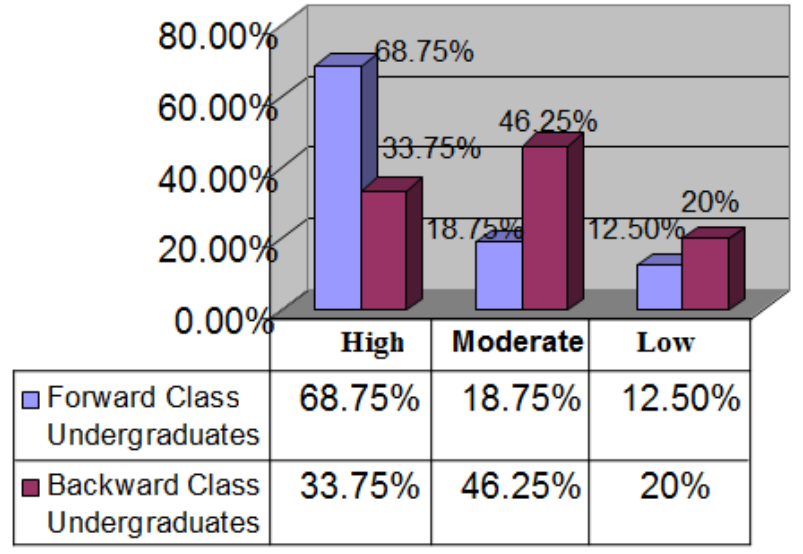

$\square$ Forward Class Undergraduates

口 Backward Class Undergraduates

Table-4: Showing Significant Difference between Male and Female Undergraduates Belonging to Forward Class Caste in terms of their degree of Morality in Mithila Region of North Bihar

\begin{tabular}{|l|l|l|l|l|l|}
\hline GROUPS & N & Mean & S.D & t & Significance Level \\
\hline Male Undergraduates & 40 & 194.63 & 31.35 & \multirow{2}{*}{$\mathbf{4 0 1 8}$} & Insignificant \\
\cline { 1 - 4 } Female Undergraduates & 40 & 193.35 & 28.22 & & \\
\hline
\end{tabular}

In addition to the above results, it can also be observed from the table-4 regarding significant difference between male and female undergraduates belonging to forward class caste in terms of their degree of morality especially from where the present piece of research work has been carried out. From the Table-4, it is apparently clear that the mean scores of both the group (male and female) has been found more or less same, Hence, significant difference has not been found between the group of male and female group belonging to forward class caste especially in Mithila region. Thus, the hypothesis formulated i.e. there will be no significant difference between the group male and female undergraduates belonging to forward class group especially in Mithila region stands accepted.

Table-5: Showing Significant Difference between Male and Female Undergraduates Belonging to Backward Class Caste in terms of their degree of Morality in Mithila Region of North Bihar

\begin{tabular}{|l|l|l|l|l|l|}
\hline GROUPS & N & Mean & S.D & t & Significance Level \\
\hline Male Undergraduates & $\mathbf{4 0}$ & $\mathbf{1 8 2 . 2 3}$ & $\mathbf{2 7 . 2 1}$ & \multirow{2}{*}{1.15} & Insignificant \\
\cline { 1 - 4 } Female Undergraduates & $\mathbf{4 0}$ & $\mathbf{1 7 5 . 3 1}$ & $\mathbf{2 5 . 6 7}$ & & \\
\hline
\end{tabular}

Similarly, Table-5 of the obtained results have clearly shown that there is no significant difference between the group of male and female undergraduate students belonging to backward class group in Mithila region of North Bihar, although, male undergraduate students have scored higher degree $($ Mean $=182.23$ with an SD 27.21) in comparison to female group belonging to backward class (Mean $=175.31$ with an SD 25.67), but instead of this, it has been found statistically insignificant. Hence the proposed hypothesis i.e. there will be no significant difference between the group of male and female undergraduates belonging to backward class group in Mithila region also stands accepted. The obtained results also seem to logical in the sense that in every society, there are there are in some - form of other group such as status group based on power, privileges and prestige. Those who have more power and privileges belong to higher social strata based on their economy and it is known as privileged class. On the contrary, those who have less power and privileges belongs lower social strata. Consequently, it is known as unprivileged class (Backward, SC, and ST Caste). By looking at the facts that it is important to point out here that during the different periods of history, it is seen that different societies had different systems of distribution of power and privileges and the system of distribution in the same socio-cultural milieu during different periods of history have also been different. As a result of this the system of social stratification has changed time to time. Psychologists and behaviorists guides to behavior that are regarded as moralities normally involve avoiding and preventing harm to others [13], and perhaps some norm of honesty [14]. But all of them involve other 
matters as well, and Hare's view of morality as that which is most important allows that these other matters may be more important than avoiding and preventing harm to others [15-17]. This view of morality as concerning that which is most important to a person or group allows matters related to religious practices and precepts, or matters related to customs and traditions, e.g., purity and sanctity, to be more important than avoiding and preventing harm.

Recent studies also document the ways in which shared social identities and group-specific moral norms may affect moral reasoning [18], affect moral behaviors, and overrule individual convictions as people seek to receive respect from other in group members $[19,20]$.

Thus, the present study was aimed at studying the perceived morality among undergraduate students belonging to forward and backward caste with particular reference to Mithila region of North Bihar. Hence, after testing the hypotheses, it has been found high significant difference between the group of forward and backward class in terms of their degree of morality.

\section{CONCLUSIONS}

On the basis of obtained results and its interpretations the following conclusions have been drawn:

1. Significance of difference has been found between the group of forward class and backward class undergraduate students in terms of their perceived reactions on morality in Mithila region of North Bihar.

2. Forward class (Upper Caste) has been found more prone to higher degree of morality than backward class (SC/ST and OBC) especially in Mithila region.

3. Significance of difference has not been found between the male and female undergraduates belonging to forward class in terms of their degree of morality in Mithila region from where the present study has been carried out.

4. Significance of difference has also not been found between the group of male and female undergraduate students belonging to backward class group in terms of their degree of perceived morality in Mithila region of North Bihar.

5. Observations have revealed the fact that the undergraduates belonging to forward class group have complete protection from their parents in comparison to backward class group especially in Mithila region. State Governments are running various programs for the complete protection of backward class in all respects but still data shows that there is a communication gap to achieve the targets. Therefore, it is suggested that more program should be run by Govt., NGOs and academicians their best survival on the earth. It is generally believed that children by imitating adults acquire more values. It is because of the fact that the degree of moral behavior will depend upon the instructions of moral values. This common sense view of morality has been criticized because it fails to explain any novelty in moral judgment. The common sense of moral acquisition has been generally opposed by the structural development but the basis objection to this view is that a person works out his own sense of morality through actively, structuring and restructuring his / her social experiences [21]. At last but not the least it is also suggested that counseling program for the upliftment of backward class group is more needed to change their lifestyle pattern based on value education.

\section{REFERENCES}

1. Haidt, J., \& Kesebir, S. (2010). Morality. In Fiske, S., Gilbert, D., Lindzey, G. (Eds.), Handbook of social psychology (5th ed., pp. 797832). Hoboken, NJ: Wiley.

2. Gert, B. (1988). A new justification of the moral rules. Oxford, UK: Oxford University Press.

3. de Waal, F. B. M (1996). Good natured (No. 87). Cambridge, MA: Harvard University Press.

4. Greenberg, J. S., \& Cropanzano, R. (Eds.). (2001). Advances in organizational justice. Stanford, CA: Stanford University Press.

5. Haidt, J., \& Graham, J. (2007). When morality opposes justice: Conservatives have moral intuitions that liberals may not recognize. Social Justice Research, 20:98-116.

6. Harvey, A. J., \& Callan, M. J. (2014). Getting “just deserts" or seeing the "silver lining": The relation between judgments of immanent and ultimate justice. PLoS ONE, 9(7):1-8.

7. Haidt, J. (2006). The Happiness Hypothesis: Finding Modern Truth in Ancient Wisdom, New York: Basic Books.

8. Hauser, Marc (2006). Moral Minds: How Nature Designed our Universal Sense of Right and Wrong, New York: Harper Collins.

9. Churchland, P. S. (2011). Braintrust: What neuroscience tells us about morality. Oxford, UK: Princeton University Press.

10. Sinnott-Armstrong, W. (ed.) (2008). Moral Psychology Volume 1. The Evolution of Morality: Adaptations and Innateness, Cambridge, MA: MIT Press.

11. Sinnott-Armstrong. (2016). The Disunity of Morality, in Liao 2016: 331-354.

12. Pandey, N. K. (1985). Morality Questionnaire Test. Unpublished thesis, L. N. Mithila University, India.

13. Frankena, William (1980), Thinking about Morality, Ann Arbor, MI: University of Michigan Press. 
14. Strawson, P. F. (1961). Social Morality and Individual Ideal. Philosophy, 36(136): 1-17.

15. Hare, R. M. (1952). The Language of Morals, New York: Oxford University Press.

16. Hare, R. M. (1963). Freedom and Reason, New York: Oxford University Press.

17. Hare, R. M. (1981). Moral Thinking, New York: Oxford University Press.

18. Gao, W., Chen, M., \& Li, Y. (2016). Descriptive norms influence reactions to anger-related moral events. Asian Journal of Social Psychology, 19(1):31-39.
19. Bizumic, B., Kenny, A., Iyer, R., Tanuwira, J., \& Huxley, E. (2017). Are the ethnically tolerant free of discrimination, prejudice and political intolerance? European Journal of Social Psychology, 47(4), 457-471.

20. Mooijman, M., Hoover, J., Lin, Y., Ji, H., \& Dehghani, M. (2018). Moralization in social networks and the emergence of violence during protests. Nature Human Behaviour, 2:389-396.

21. Piaget, J. (1932). The moral judgment of the child. New York: Marnout Brace. 